\section{Prevention rather than cure}

SIR - An innovative precautionary principle is emerging in international environmental policies of northwest Europe and Scandinavia'. The precautionary approach is encouraging new thinking through its emphasis on clean production methods and prevention of environmental contamination in the belief that it is cheaper, easier and more practical to prevent pollution in the first place than to try to clean contaminated systems later on ${ }^{2}$. As M. MacGarvin observes ${ }^{3}$, the precautionary ideal arises from recognition that scientific understanding of ecosystems is complicated by a host of factors, including complex and cascading effects of human activities and uncertainty introduced by naturally chaotic population dynamics.

Precaution also serves as a progressive policy tool. The principle addresses a key question for environmental managers: how should policies be decided in the face of scientific uncertainty? The response from science is to engage in further rigorous studies better to understand the hidden workings of nature. But a similar response is not available within the culture of policy; in a setting that must cope with demands for economic growth, the pressures for resource extraction are immense. So important policy decisions (including continuing the status quo) are made despite poor knowledge of the ultimate effects of anthropogenic activities; this situation is proving increasingly problematic for modern environmental management.

Precautionary thinking counters traditional regulatory emphasis on 'end of pipe' pollution control technologies. Moreover, precaution fundamentally rejects assimilative capacity — for instance of the coastal oceans - as a convenient means of (hoped-for) dilution. Vague definitions of precautionary action are evolving as it is increasingly applied. Initially the principle was put forward in an international setting at the first ministerial conference on North Sea pollution in Bremen in 1984 (ref. 4); it was strengthened at the second North Sea conference in 1987 (London) and further reinterpreted at the third conference in 1990 (The Hague $)^{1-4}$. The approach now appears in non-marine applications such as regulating pesticides in Africa (Bamako Convention, 1990), and efforts to reduce atmospheric contamination (Second World Climate Conference, 1990) ${ }^{5}$.

In sum, the emerging precautionary principle could become an important new link between science and policy. When first suggested, precautionary action was intended mainly to reduce marine contamination due to synthetic chemicals and heavy metals, and to halt dangerous activities such as ocean incineration because the burden of suspicion made it prudent to prevent such activities ${ }^{3}$. In only a few years, preventive thinking behind this principle has spread to broader matters ${ }^{2}$, and may yet become an eloquent step in achieving greener paths of development. Significantly, the United States has so far resisted the precautionary concept ${ }^{1}$; whether the US position evolves towards acceptance of precautionary action will surely have much to do with the eventual fate of this rising principle.

\section{Robert J. Wilder}

Department of Political Science,

University of Massachusetts, Dartmouth,

N. Dartmouth, Massachusetts 02747, USA

1. Stairs, K. \& Taylor, P. in International Politics of the Environment (eds Hurrell. A. \& Kingsbury, B.) 110-141 (Oxford University Press, 1992).

2. Dethlefsen, V., Jackson, T. \& Taylor, P., in Clean Production Strategies: Developing Preventive Environmental Management in the Industrial Economy (ed Jackson, T.) 41-62 (Lewis, Boca Raton, 1993).

3. MacGarvin, M. Helgolander Meeresunter 49, in the press (1994).

4. Gundling. L. IntlJ estuarine coastal Law5, 23-30 (1990).

5. Weintraub. B. A. N.Y.U. envtl. Law J. 1. 173-223(1992)

\section{Malaria and AIDS}

SIR - K. S. Jayaraman (Nature 378, 90; 1994) contrasts planned spending in India of US\$27 million for AIDS control with the $\$ 2$ million for the control of malaria.

But while malaria is treatable, AIDS is not. If AIDS cases increase as some have predicted, India could end up spending Rs 34,500 crore ( $\$ 11$ billion) by 2000 on one million AIDS patients. India's commitment to the control of malaria is demonstrated by the allocation of $\$ 68$ million for 1994-95 by the central and state governments, as well as additional spending by local governments, hospitals, industries and research organizations. The budget of the Malaria Research Centre for $1994-95$, for example, is $\$ 1.2$ million.

Money is not lacking, but technical and operational problems need to be tackled. In rural areas, residual spraying with insecticides is ineffective. Other problems include lack of mobility of health workers, poor supervision, delay in supplying insecticides, inability to pay wages, demoralized staff and frequent transfers.

The result is a lack of understanding of the different types of malaria, some of which are appearing in areas previously free of the disease. In some places, malaria does not respond to DDT, and reservoirs of the disease remain. Other areas have drug-resistant strains.

In short, malaria is getting out of control. What is needed is local knowledge of the dynamics of malaria transmission together with sound knowledge of the biology of vectors to produce an appropri- ate mix of technologies with which to combat the disease. Unfortunately, however, knowledge about malaria is diminishing in countries where it is endemic.

Knowledge, not money, is the key to defeating malaria.

\section{V.P. Sharma}

Malaria Research Centre,

22 Sham Nath Marg

Delhi-110054, India

\section{Vatican error?}

SIR - If all members of the new Pontifical Academy for Life "must be prepared to acknowledge that life begins at the moment of conception" (Nature 368, 90; 1994), one must agree with Gerard F. LeBlond (Nature 369, 352; 1994) that this is indeed problematic. That is because, although both ovum and spermatozoa are certainly alive, destroying them before the egg is fertilized must be morally neutral.

But what the Vatican presumably meant was that it is a new genetically unique living organism that begins its life at the "moment of conception" and that, because this can be expected to complete its full development unless it dies, then intentionally to destroy it does present ethical and theological problems. That is all the more the case because for several days after conception one cannot say that a new individual life has begun, because there is still a possibility that the fertilized egg may develop into genetically identical twins.

\section{B. Goodhart}

Gonville \& Caius College,

University of Cambridge,

Cambridge CB2 1TA, UK

\section{Blinkered review}

SIR - In his somewhat blinkered review of Kitty Ferguson's The Fire in the Equations (Nature 369, 198; 1994), Frank Tipler makes the absurd claim that scientists could "only take God-talk seriously" if it led to statements such as "If God exists, the top quark must have a mass of $185 \pm 20$ Gev". It would be pretty odd to decline to take a physical theory seriously if it did not lead to so specific a prediction. To apply the criterion to the evaluation of a metaphysical understanding involving questions of meaning and purpose (for that is what theism is about) is just an elementary category mistake. Tipler's remark is as illogical as declining to take quantum chromodynamics seriously because it tells us nothing about the significance of human existence.

\section{John Polkinghorne}

The President's Lodge,

Queens' College.

Cambridge CB3 9ET, UK 